\title{
Numerical Simulation of Detonation Wave \\ Damping Using a Layer of Granular Material
}

\author{
Ahmed A. Sileem \\ Dept. of Mech. Power Eng. Faculty of Eng., \\ Minufiya University, Shebin El-Kom, Egypt.
}

\begin{abstract}
ABSRACT
Damping or quenching of detonation wave is of great importance for safety of people, buildings, factories of chemical industries and equipment. In the present paper a layer of granular material is used to achieve this purpose. The main function of this layer is to absorb substantial part of both momentum and energy of the wave. Eventually, the detonation wave is extinguished and the pressure intensity is diminished. A model is given for drag force and heat transfer exchange between gas and solid particles. The detonation wave is initiated in a stoichiometric methane-air mixture at one end of a detonation tube. A layer of granular material is attached to the other closed end. The particles and the reactive mixture in the layer form a two-phase mixture that is initially at rest and in thermodynamic equilibrium. The dynamics in the entire domain following the collision of the propagating detonation front with the gas/layer interface is investigated. The void fraction of the granular layer is assumed constant (i.e. the particles velocity is zero). The chemical reaction is assumed to be one-step reaction of Arrhenius type. The unsteady governing equations in one-dimensional domair are solved numerically. The effects of solid particle diameters, specific heat and the void fraction variations on detonation damping are found. The results show that considerable decay of detonation occurs immediately at the gas/layer interface. The decay continues along the layer until the wave is completely died out. The distance after which the wave dies out was found to decrease with the decrease of solid particles diameter and the void fraction and the increase of solid particles specific heat. The reflected shock wave (retonation) from the gas/layer interface propagates unsteadily backward and it is reflected from the closed end of the tube to strike the gas/layer interface again. The transmitted part of the latter wave dies out quickly inside the granular layer.
\end{abstract}

KEY WORDS: Detonation waves damping, granular layer, two-phase flow of gas and solid particles, numerical solution. 


\section{INTRODUCTION}

The damping of explosions whenever happens is of great importance for the safety of people, buildings and transportation of gaseous fuel. Screens of granular materials are often used to extinguish the fire, Medvedev et al. [1]. Theoretical and experimental investigation of shock wave attenuation by screen of granular material fixed in a tube was conducted by Medvedev et al. [1]. In the theoretical study they argued that the surface friction force is small compared with the form drag and may be neglected. To neglect friction force is great simplification because the induced gas velocity behind the shock wave inside the granular material is small and consequently the friction force is large. They also neglected the heat exchange between gas and solid phases. The analytical solution was found in one-dimensional domain using Witham's rule. Their theoretical and experimental results showed that the shock decays considerably as it passes through the screen of granular material. That was concluded from the pressure history recorded ahead, inside and after the screen using piezoelectric pressure transducers and also from the analytical solution.

Britan et al. [2] studied the gas filtration during the impact of weak shock wave on granular layer attached to a rigid wall. They considered the correlations obtained for packed bed in treating the momentum and energy exchange between the gas and solid particles in their one-dimensional formulation. They also assumed that the particles do not move and therefore the void fraction does not change. Their numerical and experimental results show that the gas penetrates through the granular layer following the transmitted shock. The transmitted shock strength decays as it propagates through the layer. The decay rate was found to depend on the characteristics of the granular layer. The reflected shock at gas/layer interface propagates backward. They noticed that the pressure behind the reflected shock continues to increase in a slow rate. They attributed that to the catch up of the backward propagating compression waves that emerge from the granular layer during the gas filtration with the reflected shock

Sakakita and Hayashi [3] studied also the interaction of shock wave with a powder layer experimentally and numerically. In addition to the Ergun's model for drag force between the gas and solid phases, they added a term related to the particle-particle interaction in gas and solid momentum equations. The energy exchange between phases is taken also into consideration in their one-dimensional formulation. Unfortunately, the agreement between the numerical and experimental results was poor, as they stated in their paper.

Hayashi et al. [4] numerically simulated grain dust ignition due to high temperature behind shock wave. Cornstarch was used as dust in their calculation. The Eulerian unsteady two-dimensional conservation equations were used associated with one-step overall corn starch/air reaction. Their results gave two-phase C.J detonation and the two phases have lags in temperature and velocity fields. 
In an attempt to simulate shock wave interaction with a slab of foam attached to solid wall, Sileem [5] assumed that the foam material consists of solid particles suspended in air as suggested by Al-Mokkadem et al. [6]. The momentum and energy exchange between air and particles was modeled as that of packed bed, Bird et al. [7]. A numerical solution of the conservation equations of the two-phase mixture was obtained in one-dimensional domain. The results showed that when the shock strikes the gas/foam interface, a transmitted shock penetrates through the foam slab and also compresses it. Therefore, its length decreases and the volume fraction of solid particles increases. When the transmitted shock strikes the end wall, the pressure increases and the shock is reflected back into the foam. The pressure near the wall relaxes and the foam expands again to a certain extent. Following the strike of the incident shock with the gas/foam interface, a reflected shock is formed and propagates backward. The numerical pressure histories were compared with similar experimental records made by Skews [8] and good agreement was found.

Al-Mokkadem et al. [6] studied experimentally detonation waves damping using a specimen of foam attached to the closed end of a detonation tube and coated completely with aluminum foil in order to prevent the combustible gas from penetrating into the foam specimen. Different specimen lengths, foam materials and initial pressures in the tube were considered. The pressure records showed that the detonation wave is damped considerably. The detonation wave died completely when the length reaches certain values. These values increased as the initial pressure, in the tube, is increased. In their theoretical calculations they modeled the foam as two-phase mixture of inert solid particles and reactive gaseous mixture of acetylene and air. They assumed also that the velocity and temperature of gas and solid phases are equal.

Sileem [9] investigated the initiation and propagation of detonation wave in two-phase mixture of reactive gaseous mixture and solid spherical particles. It is assumed that the velocity and temperature of both phases are equal, following Suzuki et al. [10] and Al-Kokkadem et al. [6]. The results showed that the rate of ignition energy necessary for the initiation of detonation increases as the volume fraction of solid phase increases. It showed also that the detonation wave speed and strength decrease with the increase of volume fraction of solid particles.

The literature review revealed that the majority of experimental and numerical studies focused on shock wave attenuation or decay e.g. $[1,2,3,8]$, Skews et al. [11], Radolfo [12], Baer [13] and Baer and Nunziato [14] and Gvozdeva et al.[15], even though, detonation wave is the most dangerous and it's attenuation or extinguishing is of great importance for safety of people, buildings and factories. It has also bad impact on environment. Most of the modeling efforts concerning momentum and energy exchange between solid and gas phases in granular layer were based mainly on Ergun's model of packed bed. Therefore, an attempt of detonation wave attenuation modeling was the objective of the present work. 
In the present work, a numerical simulation of detonation wave damping using a layer of granular material is investigated. The left-hand part of the detonation tube, shown in figure 1, contains stoichiometric methane-air mixture only, while the right-hand part contains a two-phase mixture of gaseous reactants and solid particles. The detonation wave is initiated in the left-hand part of the tube. The reaction rate is a simple one-step reaction of Arrhenius type. The unsteady governing equations in one-dimensional domain are solved numerically. The effects of particles diameter, specific heat and the void fraction on detonation damping are found.

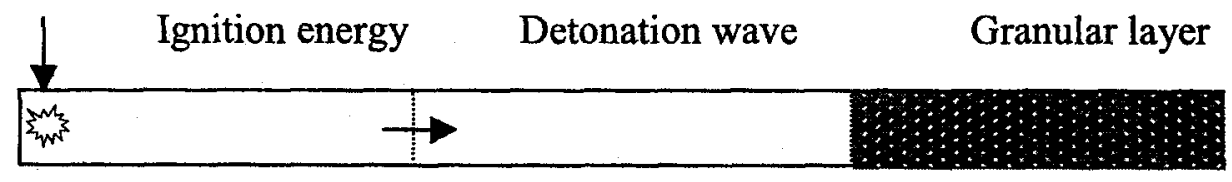

Fig. 1 Schematic diagram of the detonation tube

\section{ASSUMPTIONS}

The following assumptions are employed:

1- The solid particles are inert, spherical in shape and uniformly distributed inside the granular layer.

2- The reactive mixture (stoichiometric methane-air mixture) is assumed to be an ideal gas with constant specific heats and Prandtle number.

3- The chemical reaction is a simple one-step reaction and obeys Arrhenius rate law.

4- The particles velocity is assumed to be zero.

5- Momentum and energy transfer between phases is allowed.

6- The flow is unsteady and in one-dimensional spatial domain.

\section{GOVERNING EQUATIONS}

Various models have been suggested in the literature for the drag force and heat transfer exchange between solid and gas phases in two-phase flow in granular layer. Medvedev et al. [1] in their work about shock waves attenuation by screens of granular material used a simplified form of Ergun's equation for momentum exchange between gas and solid phases and neglected the energy exchange between the two-phases. The model of momentum and energy exchange for packed bed Bird et al. [7] is used by Britan et al. [2] in their work about shock wave interaction with granular layer and by Baer and Nunziato [14] in their work about deflagration to detonation transition (DDT) in reactive granular materials. The model for momentum and heat exchange in packed bed, Bird et al. [7] will be used in the present work, as well. Based on the assumptions cited above, the equations governing the one-dimensional 
unsteady two-phase flow (reactive gas and solid particles) are written below in semi-conservative forms.

The continuity, momentum and energy equations of the gas phase are:

$$
\begin{aligned}
& \left(\rho_{\mathrm{g}}\right)_{\mathrm{t}}+\left(\rho_{\mathrm{g}} \mathrm{u}_{\mathrm{g}}\right)_{\mathrm{x}}=0 \\
& \left\lceil u_{\mathrm{g}} \rho_{\mathrm{g}}\right\rceil_{t}+\left[\rho_{\mathrm{g}} u_{\mathrm{g}}{ }^{2}+p_{\mathrm{g}}\right]_{x}=-\frac{F}{\varepsilon_{\mathrm{g}}} \\
& {\left[E_{\mathrm{g}}\right]_{t}+\left[\left(E_{\mathrm{g}}+p_{\mathrm{g}}\right) u_{\mathrm{g}}\right]_{x}=\frac{-q_{\mathrm{g}}+F u_{g}}{\varepsilon_{g}}+q_{i}+q_{c h}}
\end{aligned}
$$

The mass fraction of reactants conservation equation is:

$$
\left\lceil y \rho_{g}\right\rceil_{t}+\left\lceil\rho_{g} u_{g} y\right\rceil_{x}=-w
$$

The gas equation of state is:

$$
p_{g}=\rho_{g} R T_{g}
$$

The heat equation of solid phase is:

$$
\left[T_{s}\right]_{t}=\frac{q_{g}-F u_{g}}{\left(1-\varepsilon_{g}\right) \rho_{s} C_{s}}
$$

Where,

$$
\begin{aligned}
& E_{g}=\rho_{g}\left(C_{v} T_{g}+u_{g}{ }^{2} / 2\right), \quad w=\rho_{g} y \beta e^{-\frac{E_{o}}{R T_{g}}} \\
& q_{c h}=h w
\end{aligned}
$$

The empirical correlation for heat and energy exchanges between solid and gas phases Bird et al. [7] are given below:

$$
F=\frac{\rho_{g} u_{g}^{2}\left(1-\varepsilon_{g}\right)}{d_{s}}\left[\frac{150}{\operatorname{Re}_{s}}+1.75\right]
$$

It is worth to mention that in equation (9) Britan et al. [2] used 180 and 1.8 instead of 150 and 1.75 that are given in the original Ergun's model. The energy exchange between the two phases is:

$$
q_{g}=\frac{6 H\left(1-\varepsilon_{g}\right)}{d_{s}}\left(T_{g}-T_{s}\right)
$$

Where $\mathrm{H}$ is:

$$
H=J C_{s} \rho_{g} \varepsilon_{g} u_{g}[\mathrm{Pr}\rceil^{-2 / 3}
$$

Where the $\mathrm{J}$ factor is given by:

$$
\begin{array}{lll}
J=0.91\left(\frac{\operatorname{Re}_{s}}{6}\right)^{-0.51} & \text { for } & \left(\frac{\operatorname{Re}_{s}}{6}\right)<50 \\
J=0.61\left(\frac{\operatorname{Re}_{s}}{6}\right)^{-0.41} & \text { for } & \left(\frac{\operatorname{Re}_{s}}{6}\right)>50 \\
\operatorname{Re}_{s}=\frac{\rho_{g} u_{g} \varepsilon_{g} d_{s}}{\mu\left(1-\varepsilon_{g}\right)} & &
\end{array}
$$

The gas viscosity $\mu$ is approximated by Sutherland's formula: 
$\mu=1.71 \times 10^{-5}\left[\frac{\mathrm{T}_{\mathrm{g}}}{273}\right]^{0.73}$

The Prandtl number of the gaseous mixture is assumed constant at 0.72 . The subscripts $\mathrm{x}$ and $\mathrm{t}$ refer to derivatives with respect to space and time, respectively.

The boundary conditions at both ends of the tube are:

$u_{g}=0 ; \quad t \geq 0, \quad x=0$

$\left(T_{\mathrm{g}}\right)_{x}=\left(\rho_{g}\right)_{x}=\left(p_{g}\right)_{x}=y_{x}=0 ; \quad t \geq 0, \quad x=x_{\max }$

The initial conditions are zero velocity in the whole domain and pressure, temperatures and densities of both solid and gas phases correspond to their initial rest state values.

\section{THE NUMERICAL SOLUTION}

The solution of the governing equations (1-6) are found numerically using the second-order accurate in space and time explicit MacCormack scheme [16]. The FCT model of artificial viscosity of Book et al. [17] is used here to minimize the numerical fluctuations near large gradients. The stability criterion of Courant, Fridrich and Lewy (CFL) is prevailed at each time step.

\section{RESULTS and DISCUSSION}

The numerical results are presented in dimensionless forms (denoted by '). Distances and lengths are normalized by a length of $\mathrm{L}_{0}=0.01 \mathrm{~m}$, the time by the acoustic time $\left(\mathrm{t}_{0}\right)$ of $\mathrm{L}_{\mathrm{o}}$ and the velocity by the speed of sound, $\mathrm{C}_{0}$ at the initial gaseous mixture rest state $\left(\mathrm{T}_{0}=300 \mathrm{~K}, \mathrm{P}_{0}=1\right.$ bar $)$. The gas and solid temperatures $T_{g}$ and $T_{s}$, their densities $\rho_{g}, \rho_{s}$ and the pressure are normalized by their corresponding values of gas phase at its initial state. The ratio of specific heats of solid $\mathrm{C}_{\mathrm{s}}$ to the specific heat at constant pressure of the gaseous mixture $C_{p}$ is called; $\delta=C_{s} / C_{p}$. For stoichiometric methane-air global reaction, the chemical heat release, specific heat at constant pressure, the ratio of specific heats and the gas constant are $\mathrm{h}=2788.7 \mathrm{~kJ} / \mathrm{kg}, \mathrm{C}_{\mathrm{p}}=1.082 \mathrm{~kJ} / \mathrm{kgK}$, $\gamma=1.3849, \mathrm{R}=0.300 \mathrm{~kJ} / \mathrm{kgK}$, respectively. The activation energy is $E_{\mathrm{a}}=1128$ $\mathrm{kJ} / \mathrm{kg}$ and the pre-exponential factor $\beta=4.255 \times 10^{5} \mathrm{~s}^{-1}$.

\subsection{Features of Detonation Wave-Granular Layer Interaction}

In this section, the salient features of the head-on collision between the detonation wave and the granular layer are given. Figures $2 a, b$ show the gas phase pressure and mass fraction of reactants profiles prior to and after the collision of detonation wave front with the granular layer. The particle diameter, $d_{s}^{\prime}=0.03$, the ratio $\delta=1$ and the void fraction $\varepsilon_{g}=0.65$. The dashed vertical line designates the location of the granular layer/gas interface at $X^{\prime}=$ 67.75. Prior to the collision, the shock wave pressure jump is almost 45 . 
Following the collision of the detonation wave with the gas/layer interface, the transmitted detonation pressure intensity diminishes considerably e.g. it becomes only 10 at $X^{\prime} \approx 78$. The damping continues at successive times until it dies almost completely at $X^{\prime} \approx 90$ as shown in the figure $2 \mathrm{a}$. On the other hand, the reflected shock (retonation) propagates unsteadily backward until it is reflected from the left-hand closed end of the tube. The reflected wave strikes again the granular layer interface and the transmitted shock wave propagates through the granular layer with deceleration behind the detonation wave front. However, the transmitted shock never catches up with the detonation front because both of them die very quickly because of the momentum and energy losses in the granular layer. The reflected shock wave propagates back and forth in the front of the layer interface but it becomes weaker and weaker by the time. The pressure variations ahead of and inside the granular layer show clearly the complexity of gas dynamics of the interaction process. The mass fraction of reactants ( $Y^{\prime}$ ) depicted in figure $2 b$ demonstrate that the combustion wave decelerates very rapidly inside the granular layer and it almóst stops propagation at $\mathrm{X}^{\prime} \approx 92$.
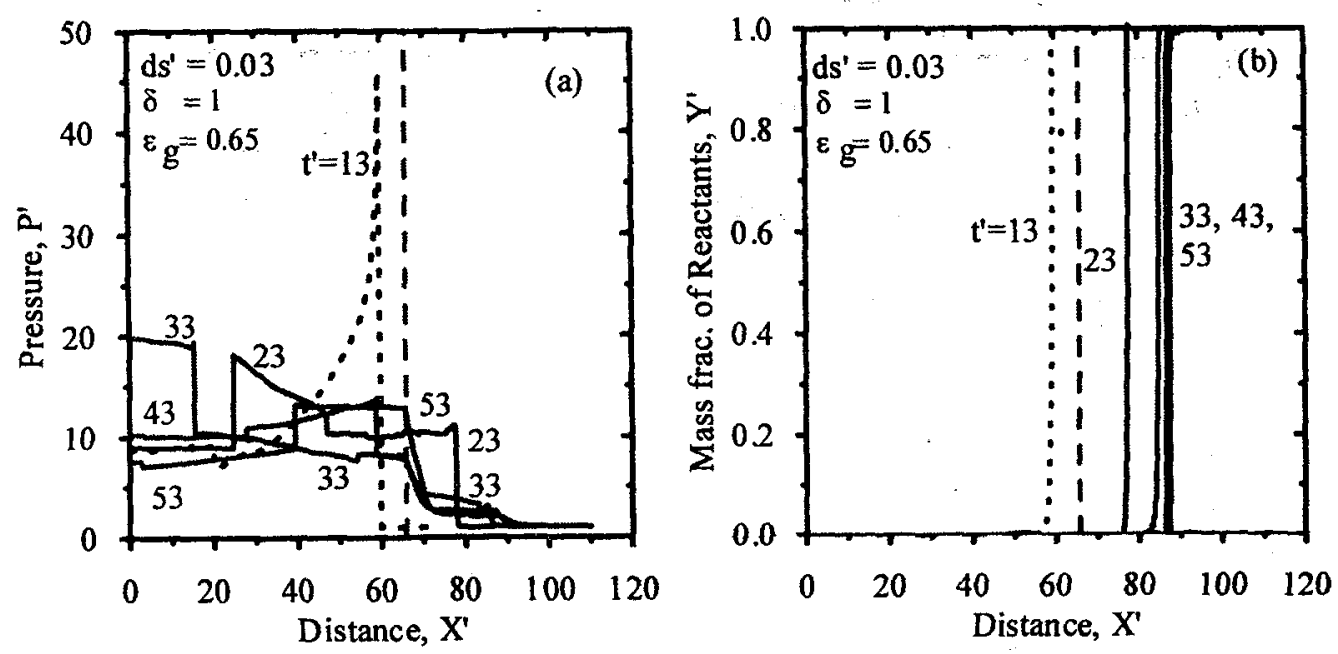

Fig. 2a, b Pressure and mass fraction of reactants at successive times.

The gas and solid temperature profiles are shown in figure $3 \mathrm{a}, \mathrm{b}$ respectively. The gas temperature decreases as the wave propagates inside the granular layer. The loss of wave energy and momentum to the solid phase is responsible for the reduction in gas temperature. On the other hand, the solid phase temperature rises sharply near the interface that is actually due to heat absorbed from the gas phase. The solid phase temperature diminishes later on because the gas temperature decreases owing to the reduction in chemical heat release associated with the slow down of the combustion wave. Figure 4 is plotted for the gas velocity at successive times. The gas velocity diminishes very rapidly following the strike of shock wave with gas/layer interface. The reflected and re-reflected shocks are clearly shown. Figure 5 shows the calculated pressure history at three locations; $X^{\prime}=40$ (ahead of the gas/layer interface), $X^{\prime}=82$ 
and 92 inside the granular layer. At $X^{\prime}=40$, the first pressure jump belongs to the detonation wave, while the other smaller jumps belong to the reflected shock wave going back and forth between the gas/layer interface and the lefthand closed end of the tube. At $X^{\prime}=82$, the detonation wave pressure intensity is damped out appreciably while at $X^{\prime}=92$, it is almost completely damped out. The damping of detonation is mainly attributed to the momentum and energy losses inside the granular layer.
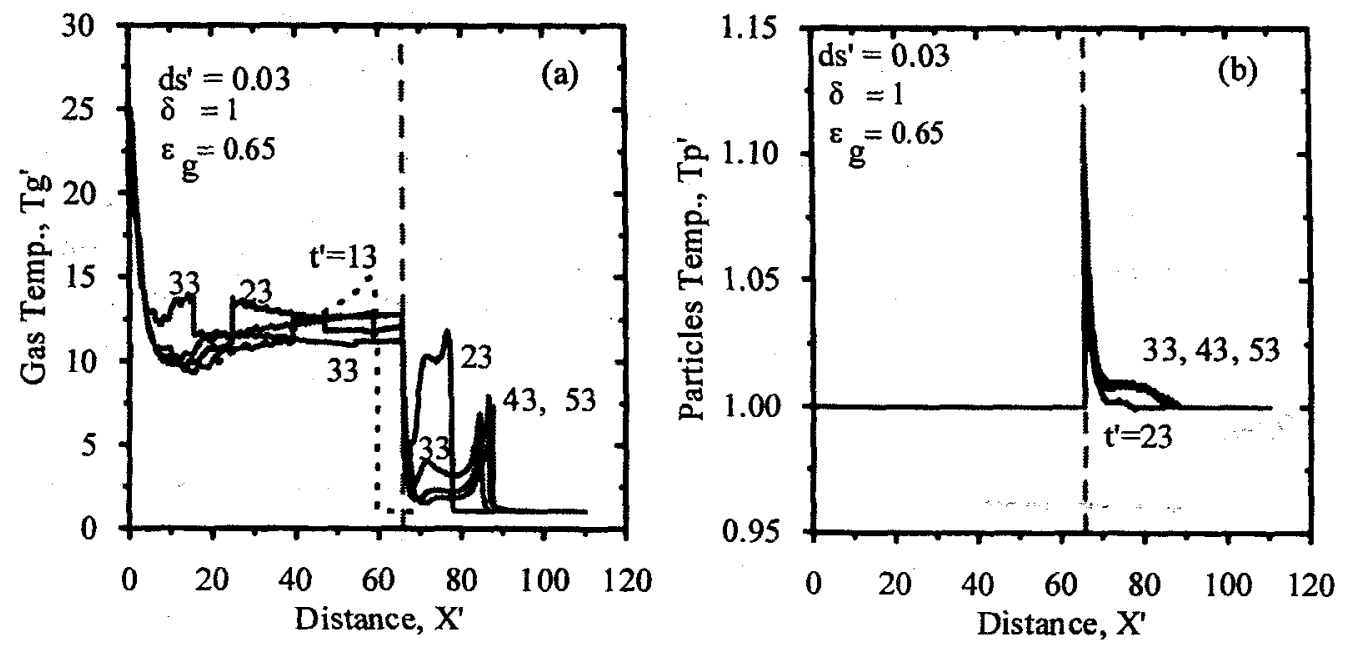

Fig. 3a, b Gas and solid temperatures at successive times.

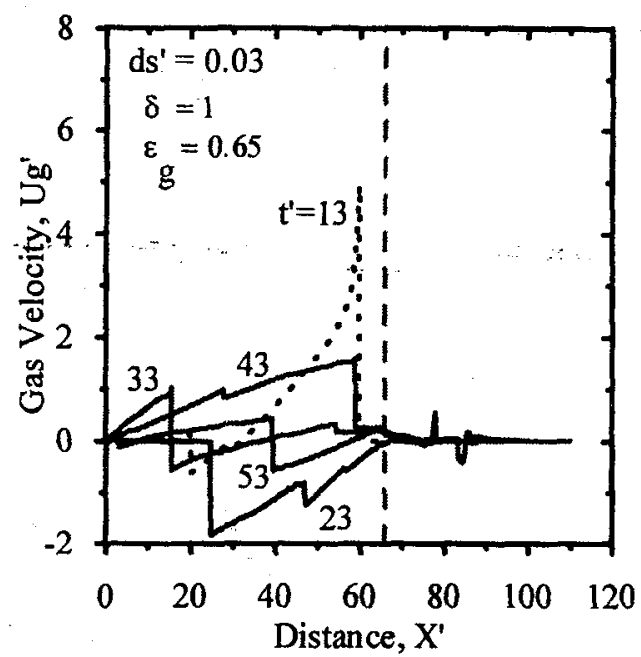

Fig.4 Gas velocity profiles at successive times.

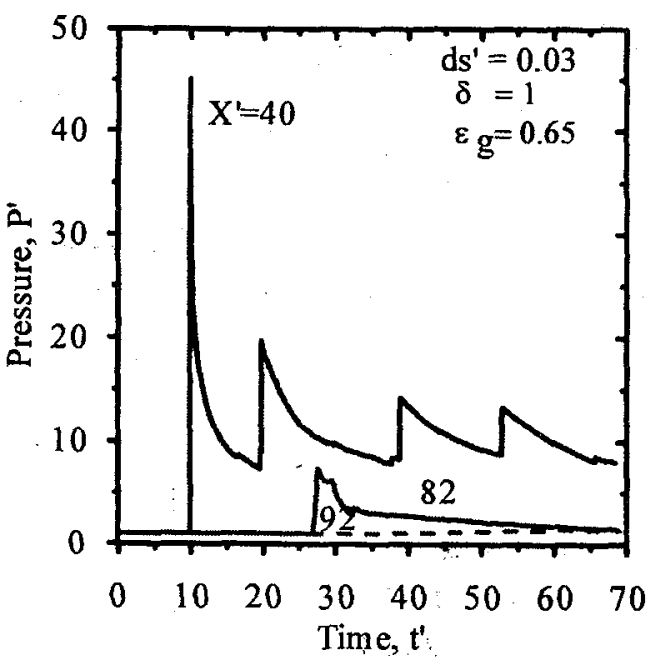

Fig.5 Pressure histories at three different locations.

\section{2. Effect of Solid Particle Diameters on Detonation Damping}

In this section the effect of solid particles diameter on detonation wave attenuation is presented. Here, the void fraction $\varepsilon_{\mathrm{g}}=0.65$ and $\delta=0.6$ are kept constants. Figures $6 \mathrm{a}, \mathrm{b}$ show the pressure and gas temperature histories calculated at $L^{\prime}=11.25 ; L^{\prime}$ is measured from gas/granular layer interface. The 
results demonstrate that the decay of detonation wave pressure intensity and gas temperature are greater for smaller diameter particles. In particular, when $\mathrm{d}_{\mathrm{s}}{ }^{\prime}=0.01$, the detonation wave is completely died out at the considered location. This is attributed to the increase in the effective surface area of smaller particles that in turn increase the friction force and heat transfer as mentioned by I-Shih Chang [18]. The dashed curve in each graph belongs to the wave ahead of the gas/layer interface. The combustion wave paths at different values of particles diameter presented in figure 7 illustrate that the granular layer with smaller diameter particles extinguish the fire quicker than that of larger diameter particles. Figure 8 shows the variation of the particles diameter with the granular layer length ( $\left.L^{\prime}\right)$ that is necessary for damping out the detonation. As depicted, the length of granular layer necessary for detonation wave damping is smaller for smaller particles diameter.
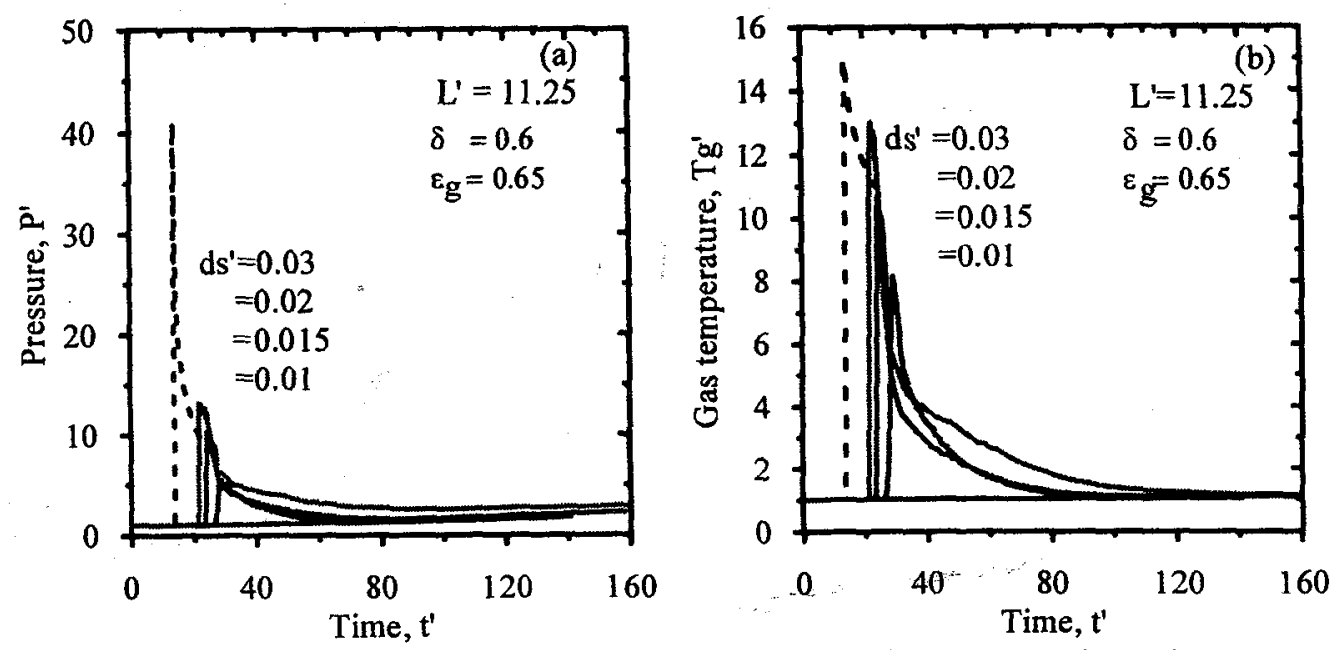

Fig. 6a, b Pressure and gas temperature histories at different particle diameters.

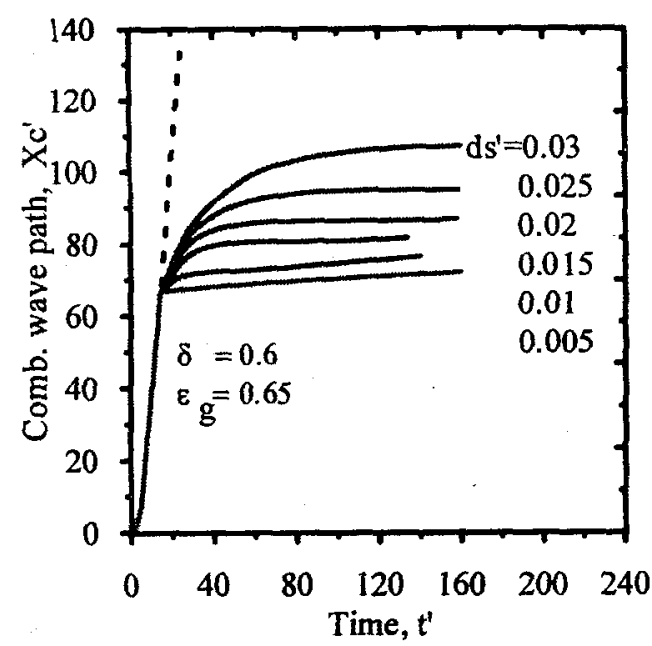

Fig. 7 Combustion wave paths at different values of particles diameter.

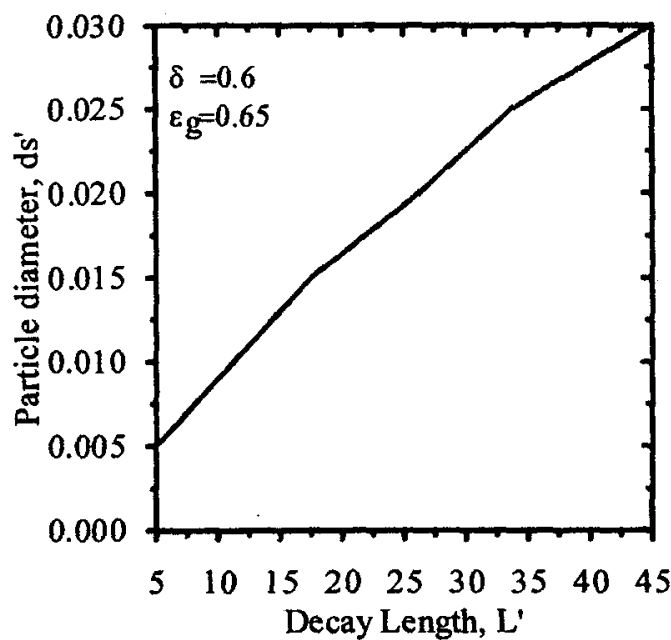

Fig. 8 Effect of particles diameter on decay length. 


\subsection{Eifect of Void Fraction $\left(\varepsilon_{\mathrm{g}}\right)$ on Detonation Damping}

Here, the particles diameter $d_{s}^{\prime}$ and the ratio $\delta$ are kept constants at 0.05 and 0.6 , respectively. In figures $9 a, b$ the pressure and gas temperature histories are plotted for different values of the void fraction $\varepsilon_{\mathrm{g}}$. Pressure intensity at the detonation front decreases appreciably after collision with granular layer interface. The front pressure becomes four times smaller after almost a distance of $L^{\prime}=16.25$ from the gas/layer interface when the void fraction is 0.4 . It gets smaller for smaller values of void fraction, as shown. A decrease in temperature is also noticed but with slower rate. In figures $10 \mathrm{a}, \mathrm{b}$ the pressure and gas temperature histories are plotted at different locations along the granular layer at $\varepsilon_{\mathrm{g}}=0.4$ in addition to the pressure and temperature ahead of the gas/layer interface. The detonation wave is almost died after almost $L^{\prime}=36$. The gas temperature depicted in figure $10 \mathrm{~b}$ confirms that conclusion.
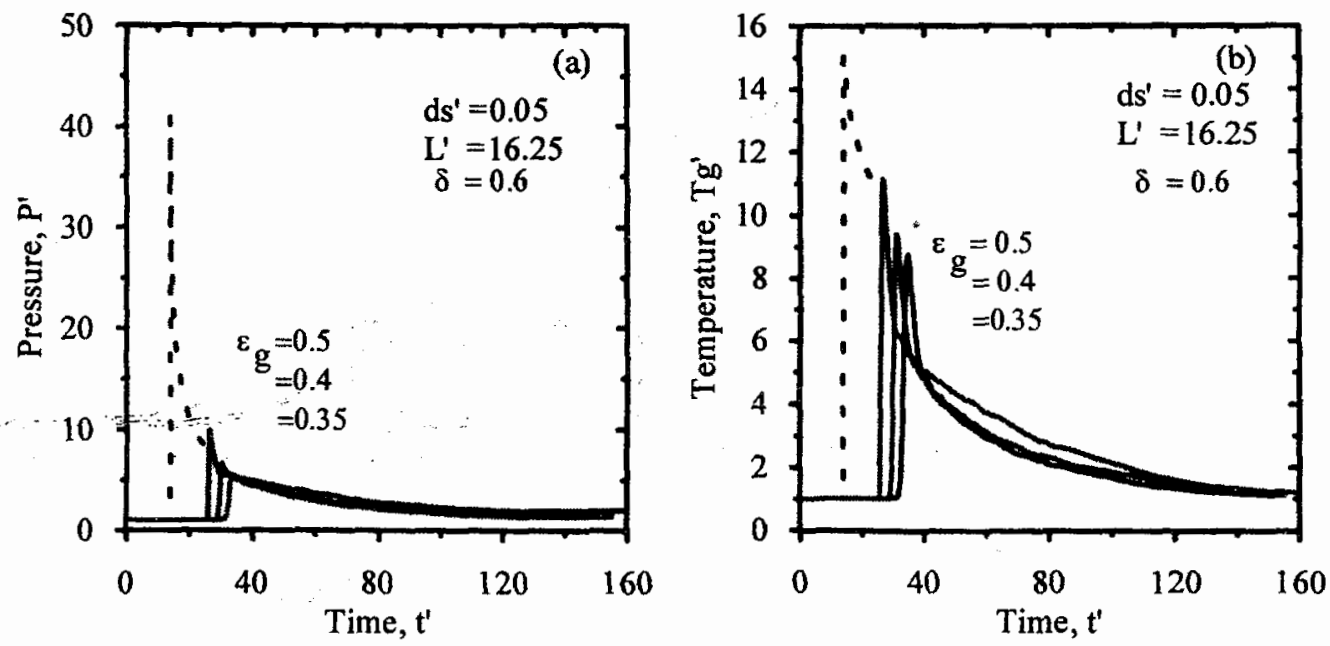

Fig. 9a, b Pressure and gas temperature histories at different values of void fraction.
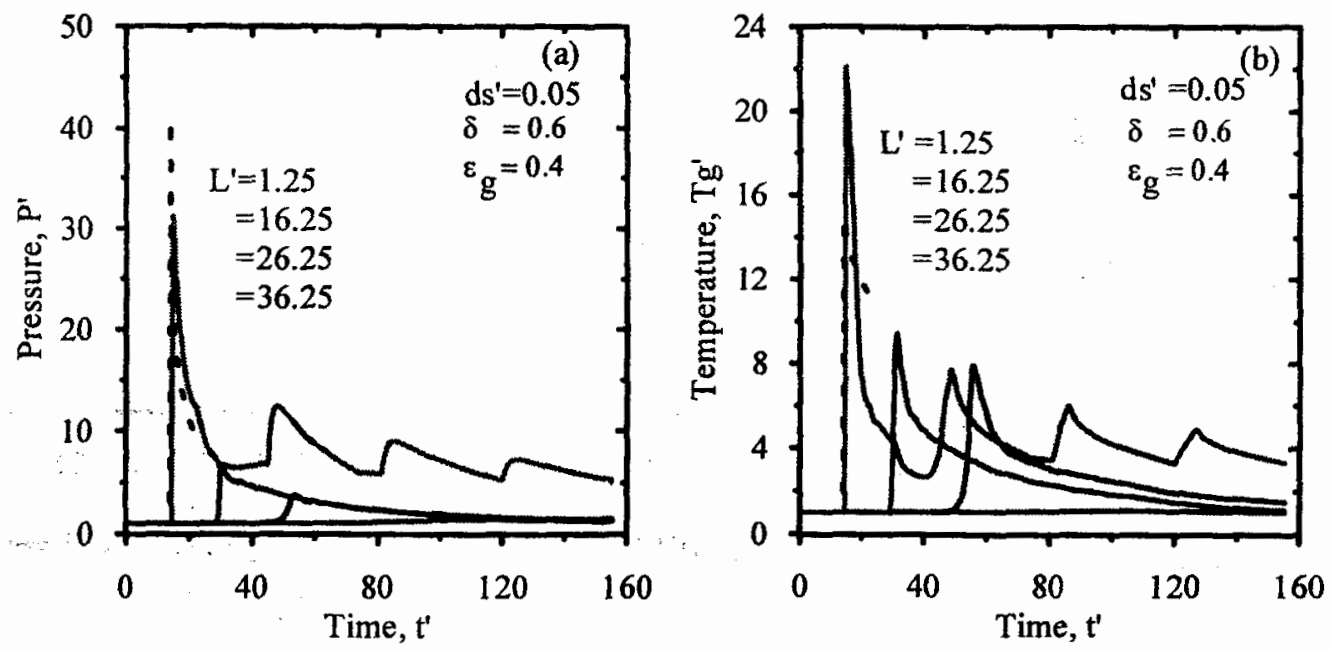

Fig.10a, b Pressure and gas temperature histories inside the granular layer. 
Figure 11 illustrates the combustion wave paths at different values of $\varepsilon_{\mathrm{g}}$ that clearly show the stopping of flame earlier as the void fraction gets smaller. There is an almost linear relation between void fraction and length after which the detonation dies out as depicted in figure 12. The decrease in void fraction means that the reactive mixture inside the granular layer is smaller. Hence, the chemical energy release necessary for self-sustained detonation is not enough to do so, therefore, it dies out.

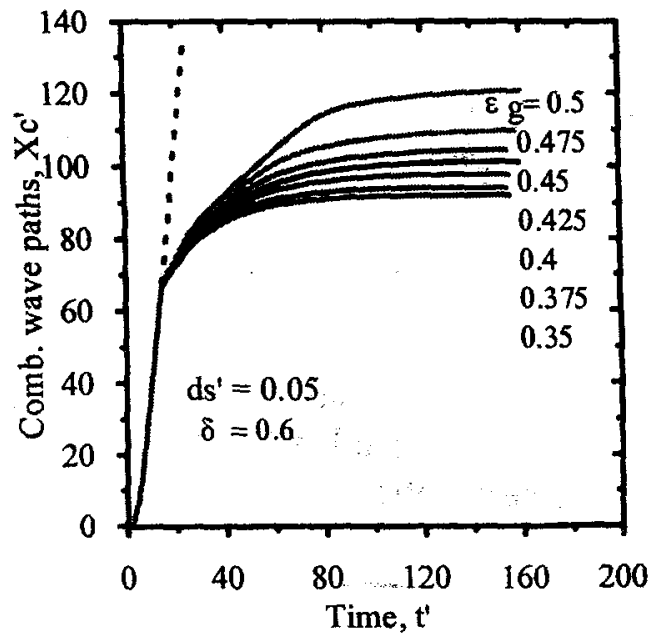

Fig. 11 Combustion wave paths at different values of void fraction.

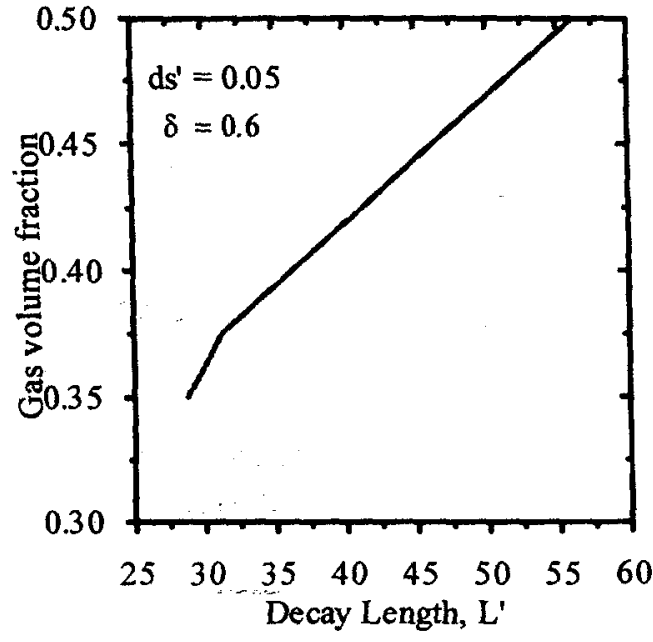

Fig. 12 Effect of void fraction on decay length.

\section{4. Effect of Specific Heat of Solid Particles on Detonation Damping}

The effect of solid particles specific heat variation is given here in terms of $\delta$. The void fraction $\varepsilon_{\mathrm{g}}=0.4$ and particles diameter $\mathrm{d}_{\mathrm{s}}{ }^{\prime}=0.05$ are kept constants. Figures $13 \mathrm{a}, \mathrm{b}$ show the pressure and gas temperature histories at $L^{\prime}=16.25$ and also ahead of the gas/granular layer interface for different values of $\delta$. The results illucidate clearly the great influence of increase in the heat capacity of solid particles on the absorbing the momentum and energy of the detonation wave. The increase of heat capacity of solid allows the same quantity of solid to absorb more energy from the surrounding hot gas. Consequently, the energy needed for self-sustained detonation diminishes and this, in turn, causes the die out of the wave. As could be seen in figures 13a, b, the pressure intensity and gas temperature at wave front are almost vanished at that location when $\delta=1.2$. Pressure and temperature histories at different locations inside the granular layer at $\delta=1$ depicted in figures $14 a, b$ demonstrate the continuous decay of the wave front pressure intensity and temperature. These variables are almost vanished at $L^{\prime}=37.75$. The jumps that appear in the pressure and temperature curves at $L^{\prime}=1.25$ are due to the transmitted part of shocks that re-reflected from the left-hand side closed end of the tube and strikes the gas/granular layer interface many times. These 
jumps show up only at that location because of its closeness to the gas/granular layer interface. At downstream locations, these jumps disappear because they die out before the arrival to these locations.
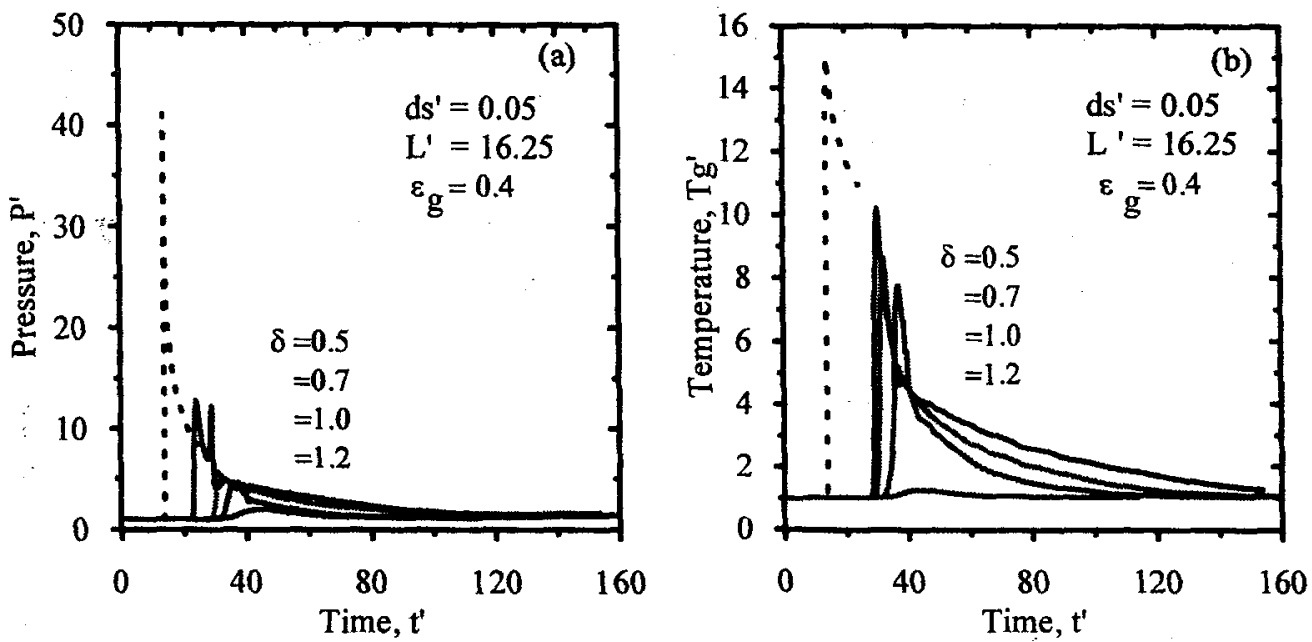

Fig. 13a, b Pressure and gas temperature histories at $\mathrm{L}^{\prime}=16.25$ at different values of specific heats ratio.
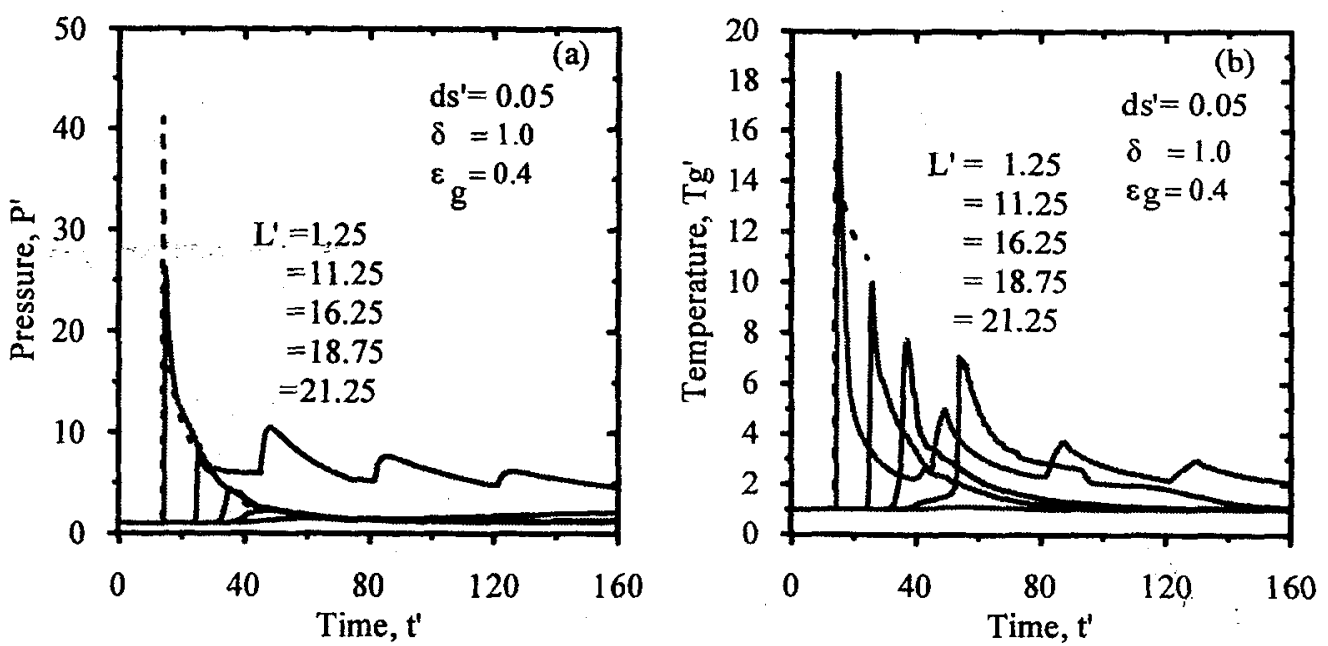

Fig. 14a, b Pressure and gas temperature histories at different locations inside the granular layer.

Figure 15 is plotted for the combustion wave paths at different values of $\delta$. It is obvious that the combustion wave stops propagation earlier as the heat capacity of solid particles increases. The variation of decay length with $\delta$ plotted in figure 16 shows an obvious increase of that length as $\delta$ gets smaller. 


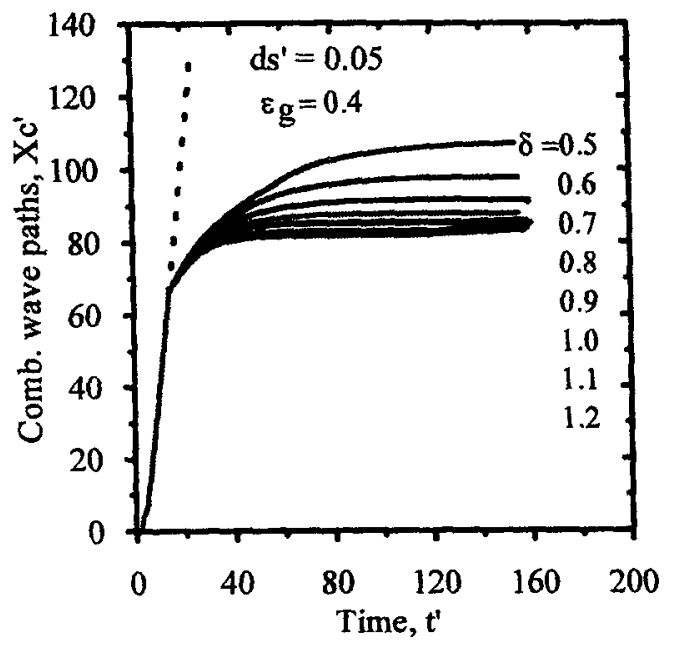

Fig. 15 Combustion wave paths at different values of specific heats ratio.

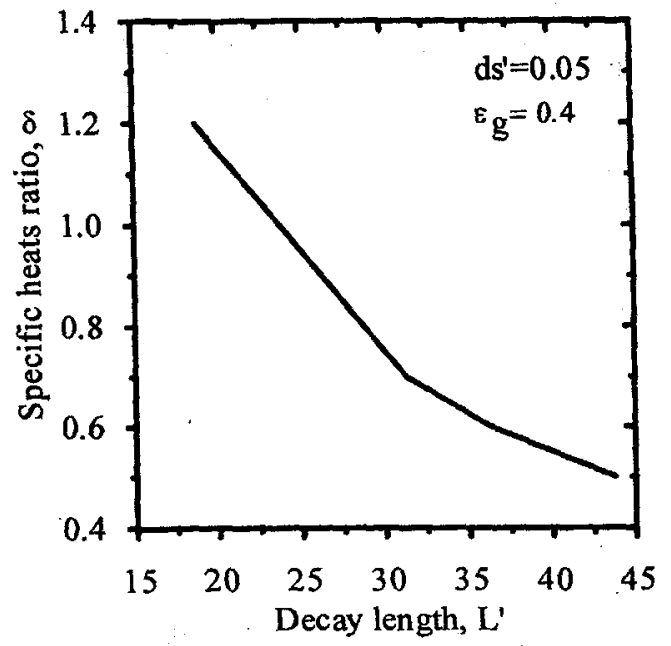

Fig. 16 Effect of specific heats ratio on the decay length.

\section{CONCLUSIONS}

The results presented in this work show that a layer of granular layer of solid spherical particles could be an effective mean for damping detonation waves or explosions. The choice of the granular layer material and the grain diameters are of great importance because of their great influence on absorbing the momentum and energy of the wave. The best choice is a material of solid particles that has high heat capacity and the grain diameters should be as small as possible. The empirical correlation for drag force and heat exchange between gas and solid particles of packed bed proved to give reasonable results.

Even though, we could not find experimental results in the literature to compare the present computational results with, the results obtained here, at least, give us some predictions.

\section{NOMENCLATURE}

$\mathrm{C}_{0} \quad$ Sound speed in gaseous mixture at rest state $(\mathrm{m} / \mathrm{s})$

$\mathrm{C}_{s} \quad$ Specific heat of solid particles $(\mathrm{kJ} / \mathrm{kg} \mathrm{K})$

$\mathrm{C}_{\mathrm{p}} \quad$ Gas specific heat at constant pressure $(\mathrm{kJ} / \mathrm{kg} \mathrm{K})$

$\mathrm{C}_{\mathrm{v}} \quad$ Gas specific heat at constant volume $(\mathrm{kJ} / \mathrm{kg} \mathrm{K})$

$E_{a} \quad$ The activation energy $(\mathrm{kJ} / \mathrm{kg})$

F Force (N)

h The chemical heat release parameter per $\mathrm{kg}$ of reactive mixture $(\mathrm{kJ} / \mathrm{kg})$

L The length measured from gas/granular layer interface (m)

$\mathrm{P} \quad$ Pressure $(\mathrm{Pa})$

Pr Prandtl number

$q_{\mathrm{ch}}$ The rate of chemical heat release ( $\mathrm{kg} / \mathrm{kg}$ of reactants) 


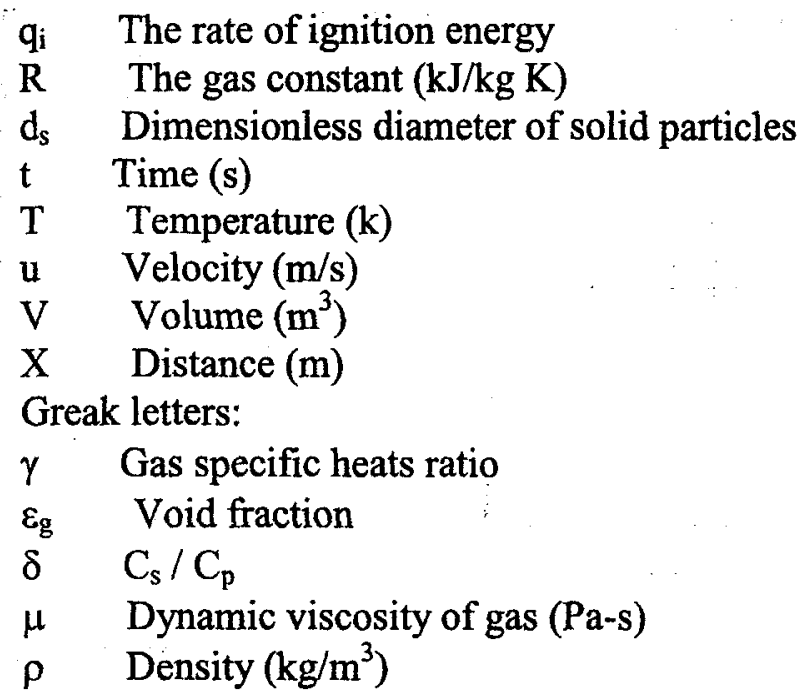

Subscripts:

o Atmospheric conditions.

g Gas phase

s Solid phase

\section{REFERENCES}

1- S. P. Medvedev, S. M. Prolov and B. E. Gel'fand ' Attenuation of shock waves by screens of granular material' J. of Eng. Physics, Vol. 58, No. 6, June, 1990

2- A. Britan, G. Ben-Dor, T. Elperin, O. Igra and J. P. Jiang ' Gas filtration during the impact of shock waves on granular layers' Int. J. Multiphase Flow, Vol. 23, No. 3, pp. 473-491, 1997

3- Hajime Sakakita and A. K. Hayashi ' Study on the interaction between a powder layer and a shock wave' $18^{\text {th }}$. (Int.) Symp. on Space Tech. and Science, Kagoshima, May 17-23, 1992

4- A. Hayashi, Takayuki Fuyuto and Toshi Fujiwara ' Numerical simulation of shock waves through combustible two-phase media' Shock Waves, Springer_Verlag Berlin Heidelberg, pp. 191-196, 1995

5- Ahmed A. Sileem 'Numerical simulation of shock wave interaction with a slab of compressible foam attached to a solid wall' Engineering Research Journal (ERJ) Faculty of Engineering, Minufiya University, Vol. 24, No. 2, April 2001, pp.17-38, April 2001

6- Al-Mokkadem A. E., El-salamoni M. A., Elieche A. M. and Kamel M. M.' Study of the damping capacity of foam materials against detonation pressure waves' The $1^{\text {st }}$. Conference of the Egyptian combustion society. The higher Technological Institute, Ramadan $10^{\text {th }}$ City, Egypt, pp.117-139, Dec. 26-28, 1989

7- Bird, R. B., Stewart, W. E. and Lightfoot, E. N. 'Transport phenomena' J. Wiley, New York, 1960

8- B. W. Skews 'The reflected pressure field in the interaction of weak shock waves with a compressible foam`'Shock Waves 1:205-211, 1991 
9- Ahmed A. Sileem 'Initiation and propagation of detonation wave in two-phase mixture of reactive gas and inert solid particles'Proceedings of the $11^{\text {th }}$ International Mechanical Power Engineering Conference. Cairo, Egypt, Vol. 1, pp. C112-C126, Feb.(5-7) 2000

10- Suzki, T., Ohyagi, S. Higashino, F. and Takano, A. 'The propagation of reacting blast waves through inert particle clouds' Acta Astronautica, Vol.3, pp.517-529, Pergamon Press., 1976

11- B. W. Skews, M. D. Atkins and M. W. Seitz 'The impact of a shock wave on porous compressible foams' J. Fluid Mech., Vol. 253, pp.245-265, 1993

12- Radolf Monti 'Normal shock wave reflection on deformable solid wall' Meccanica 4, 285-296, 1970

13- M. R. Baer 'A numerical study of shock wave reflections on low density foam' Shock Waves 2:121-124, 1992

14- M. R. Baer and J. E. Nunziato ' A two-phase mixture theory for the deflagration-to-detonation transition (DDT) in reactive granular materials' Int. J. Multiphase flow Vol.12, No.6, pp.861-889, 1986

15- Gvozdeva, L. G., Faresov Y. M., Brossard, J. and Charpentier, N. 'Normal shock reflection on porous compressible material' $10^{\text {th }}$ ICDERS, Berkeley, U. S. A., 1985

16- R. W. MacCormack The effect of viscosity in hypervelocity impact cratering AIAA Paper 69-354, Cincinnati, Ohio, U.S.A., 1969

17- Book, W. A., Boris, J. P. and Hain, K. Flux-corrected transport II: Generalization of the method' J. of Comput. Physics 18, 248-283, 1975

18- I-Shih Chang 'One-and two-phase nozzle flows' AIAA Journal, Vol. 18, No.12, Dec., 1980 


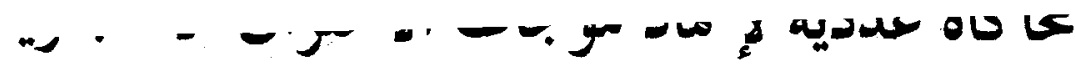

\section{بواسطة طبقة من المواد الصلبة الخببة.}

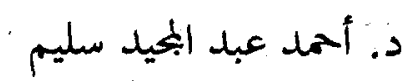

$$
\text { كلية الهندسة بشبين الكوم ـ ـ جامعة المنوفية }
$$

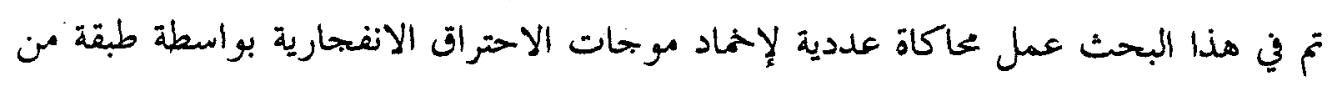

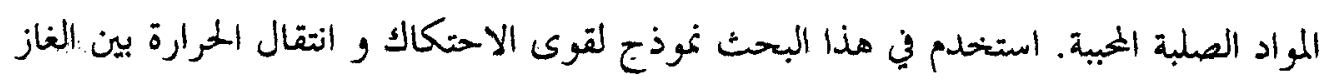

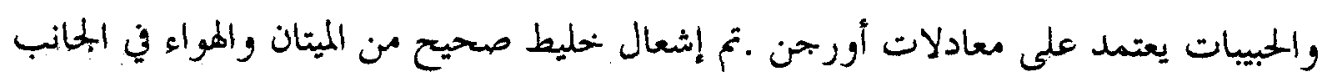

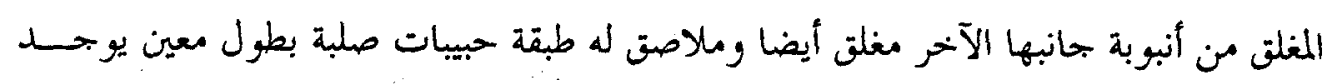

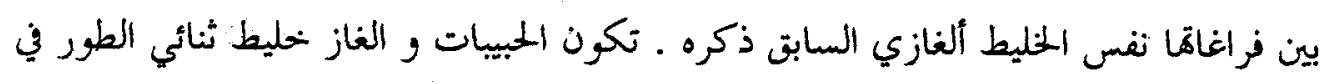

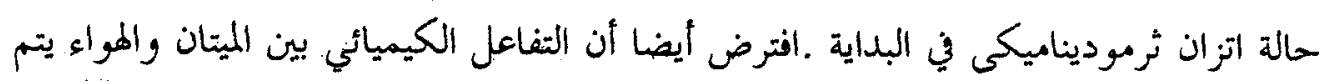

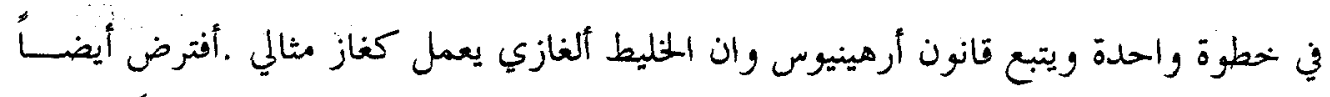

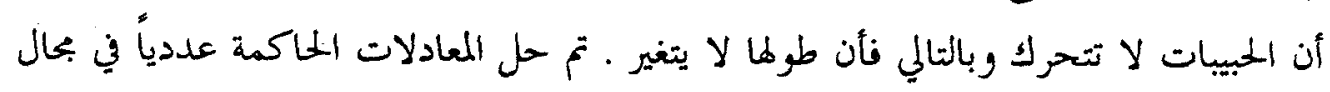
أحادى البعد. أظهرت النتائج ما يلي: - أليعل

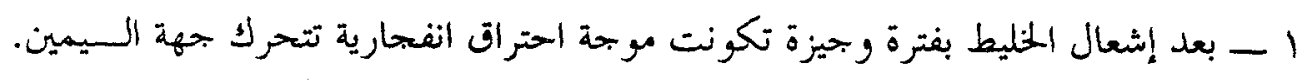

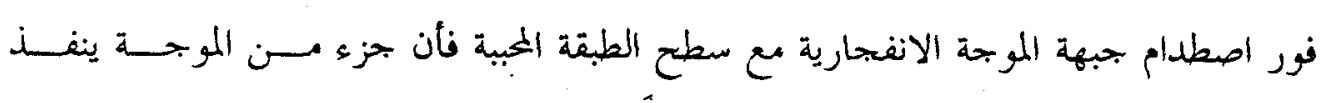

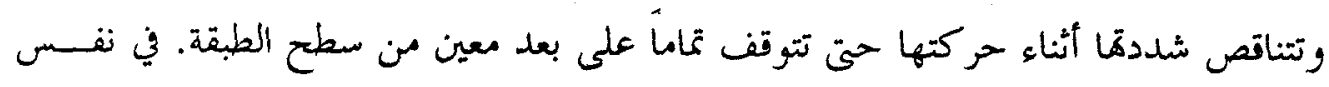

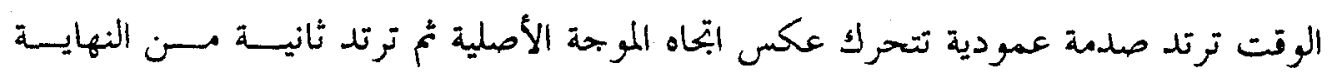

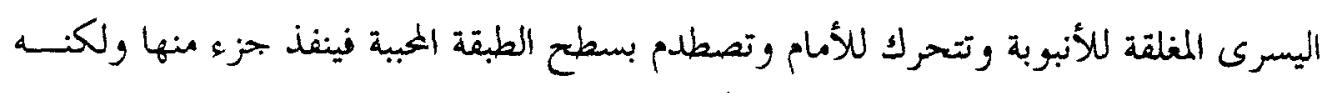
لا يلحق بموجة الإحتراق قبل أن تموت تماماً.

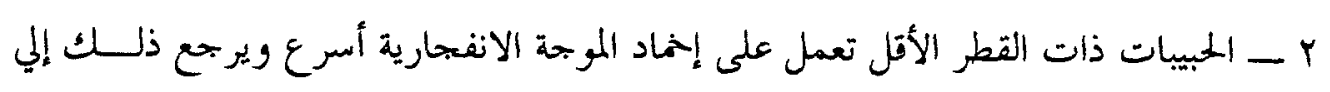
زيادة المساحة السطحية الكلية للحبيبات صغيرة القطر والتي بدورها تزيد من قوة الاحتكاك.

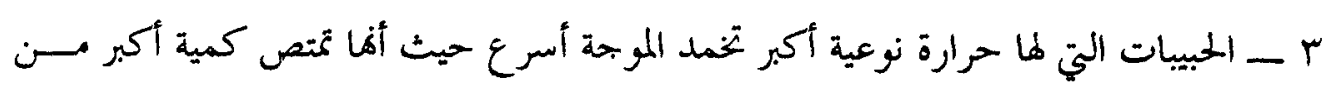
الحرارة النابحة من الاحتراق.

ع - ـ يكون الإحماد أسرع كلما زادت النسبة اللحجمية للحبيات في الخليط ثنائي الطور. 